Abstract

\title{
Sustainability at the Table ${ }^{\dagger}$
}

\author{
Emily King \\ Spira Ltd. Auckland, 1081, New Zealand; emily@spira.nz \\ + Presented at the 2018 Nutrition Society of New Zealand Annual Conference, Auckland, New Zealand, \\ 28-30 November 2018.
}

Published: 6 March 2019

How do we ensure nutritious diets in a climate change affected world? How can we protect the resources needed for food production for future generations? And can we do this in a way that benefits the soil and waterways as well as human health at the rate that is needed?

Our food system has many environmental and social impacts from production through to consumption. Taking a food systems approach can help nutritionists to understand and unpack where positive environmental and social changes can be made across that system. This approach is important for two reasons. First, most food moves constantly through a value chain and evolves as it does until it gets eaten or wasted by the end user. Secondly, food often crosses borders and countries as it follows that process, making this a global challenge.

Sustainability in this context is environmental: ensuring we maintain and improve our impact on the environment so we can ensure resources for our future generations. Bringing sustainability to the table encourages different sectors, such as health and environment professionals, to come together to solve some of our most pressing issues. Right now in the food system some of those big issues are: plastics, climate change, declining fish stocks, urban sprawl devouring our best soil, and degraded waterways. And these all impact on delivering nutritious food to people.

This presentation will cover these topics, explore what is happening globally at the interface of sustainability and health, and discuss how you can apply this to your work and personal lives.

(C) 2019 by the authors. Submitted for possible open access publication under the

terms and conditions of the Creative Commons Attribution (CC-BY) license (http://creativecommons.org/licenses/by/4.0/). 